\title{
First fossil tooth-necked fungus beetle (Coleoptera: Derodontidae): Juropeltastica sinica gen. n. sp. n. from the Middle Jurassic of China
}

\author{
Chenyang CAI ${ }^{1,2}$, John F. LAWRENCE ${ }^{3}$, AdAm ŚLIPIŃSKI $^{3}$ and DiYING HUANG ${ }^{1 *}$ \\ ${ }^{1}$ State Key Laboratory of Palaeobiology and Stratigraphy, Nanjing Institute of Geology and Palaeontology, Chinese Academy \\ of Sciences, 39 East Beijing Road, Nanjing 210008, China; e-mails: caichenyang1988@163.com, dyhuang@nigpas.ac.cn \\ ${ }^{2}$ Graduate School, University of Chinese Academy of Sciences, 19A Yuquanlu, Beijing 100049, China \\ ${ }^{3}$ Australian National Insect Collection, CSIRO Ecosystem Sciences, GPO Box 1700, Canberra ACT 2601, Australia; \\ e-mails: coleop@bigpond.com, adam.slipinski@csiro.au
}

Key words. Coleoptera, Derodontidae, Juropeltastica gen. n., fossil, Daohugou beds, Middle Jurassic, China

\begin{abstract}
The first fossil tooth-necked fungus beetle, Juropeltastica sinica gen. n. sp. n., is described and illustrated based on a single impression fossil from the Middle Jurassic Daohugou beds (ca. $165 \mathrm{Ma}$ ) of northeastern China. It represents the first definitive fossil belonging to the extant family Derodontidae. Juropeltastica is placed in Derodontidae based on its overall body shape and size, head with complex systems of tubercles and grooves, pronotum with dentate lateral carinae, open mesocoxal cavities bordered by mesepimeron and metanepisternum, excavate metacoxae, and 5-segmented abdomen. The occurrence of a reliable derodontid fossil from 165 million years ago places Derodontidae among the small but growing number of beetle families of known Middle Jurassic age, which is important in the dating of phylogenetic trees.
\end{abstract}

\section{INTRODUCTION}

With only 23 species placed in four genera (Leschen \& Beutel, 2010), the beetle family Derodontidae (or toothnecked fungus beetles) is an isolated and primitive group in Polyphaga (Crowson, 1959) placed in their own superfamily Derodontoidea in the series Bostrichiformia by Lawrence \& Newton (1995). The family was considered to be a sister taxon to Nosodendridae by Beutel (1996) and formed a clade with Nosodendridae and Scirtidae in the morphological analysis of Lawrence et al. (2011). In recent molecular studies by Hunt et al. (2007) and Bocak et al. (2014), however, Derodontidae and Nosodendridae formed two clades attached to different sections of the Polyphaga. Derodontidae consists of three subfamilies: Peltasticinae LeConte contains the single genus Peltastica Mannerheim, Derodontinae LeConte contains Derodontus LeConte, and Laricobiinae Mulsant \& Rey contains Laricobius Rosenhauer and Nothoderodontus Crowson. This arrangement has been confirmed by a recent cladistic analysis (Ge et al., 2007). The extant genera Derodontus, Laricobius and Peltastica are holarctic in distribution, whereas Nothoderodontus occurs in Chile, Australia and New Zealand (Lawrence \& Hlavac, 1979; Lawrence, 1985; Leschen, 2002; Háva, 2006; Yu \& Montgomery, 2007). Larvae and adults typically occur together in the same habitats in the temperate regions in the northern and southern hemispheres (Lawrence \& Hlavac, 1979; Crowson, 1980; Lawrence, 1982). Peltastica is present at sap flows where it feeds on fungi and other suspended nutrients while Laricobius are predators on Adelgidae (Hemiptera) (Franz, 1958; Leschen, 2011). Derodontus are found exclusively on homobasidiomycte fungi and are abundant mainly in cooler seasons (Lawrence \& Hlavac, 1979; Leschen, 1994, 2002). Nothoderodontus is associated with sooty molds (Lawrence, 1985), although some specimens have been collected in other habitats, including one new species from the flowers in tussock areas of New Zealand (Leschen \& Beutel, 2010). Adults of derodontids are characterized by the presence of paired ocelli, prothorax mostly with dentate lateral carinae, open mesocoxal cavities bordered by both mesepimeron and metanepisternum, excavate metacoxae, and rugose body form in most adults (Leschen, 2002).

Unfortunately, no definitive fossil derodontids have been reported to date, and little about the origin and early evolutionary history of the superfamily Derodontoidea is known. Here we report a new genus and species of Derodontidae from the Mesozoic of China.

\section{MATERIAL AND METHODS}

The sole specimen described here was collected from a fossil locality near Daohugou Village, Inner Mongolia, China, from which plants, diverse insects, conchostracans, anostracans, spiders, salamanders, pterosaurs, and mammals have also been discovered (Huang et al., 2006). The specimen is housed in the Nanjing Institute of Geology and Palaeontology, CAS, Nanjing, China. The specimen was observed and photographed using a Zeiss Discovery V20 stereo microscope. It was examined both dry (under low-angled light) and under 70\% alcohol.

\footnotetext{
* Corresponding author.
} 

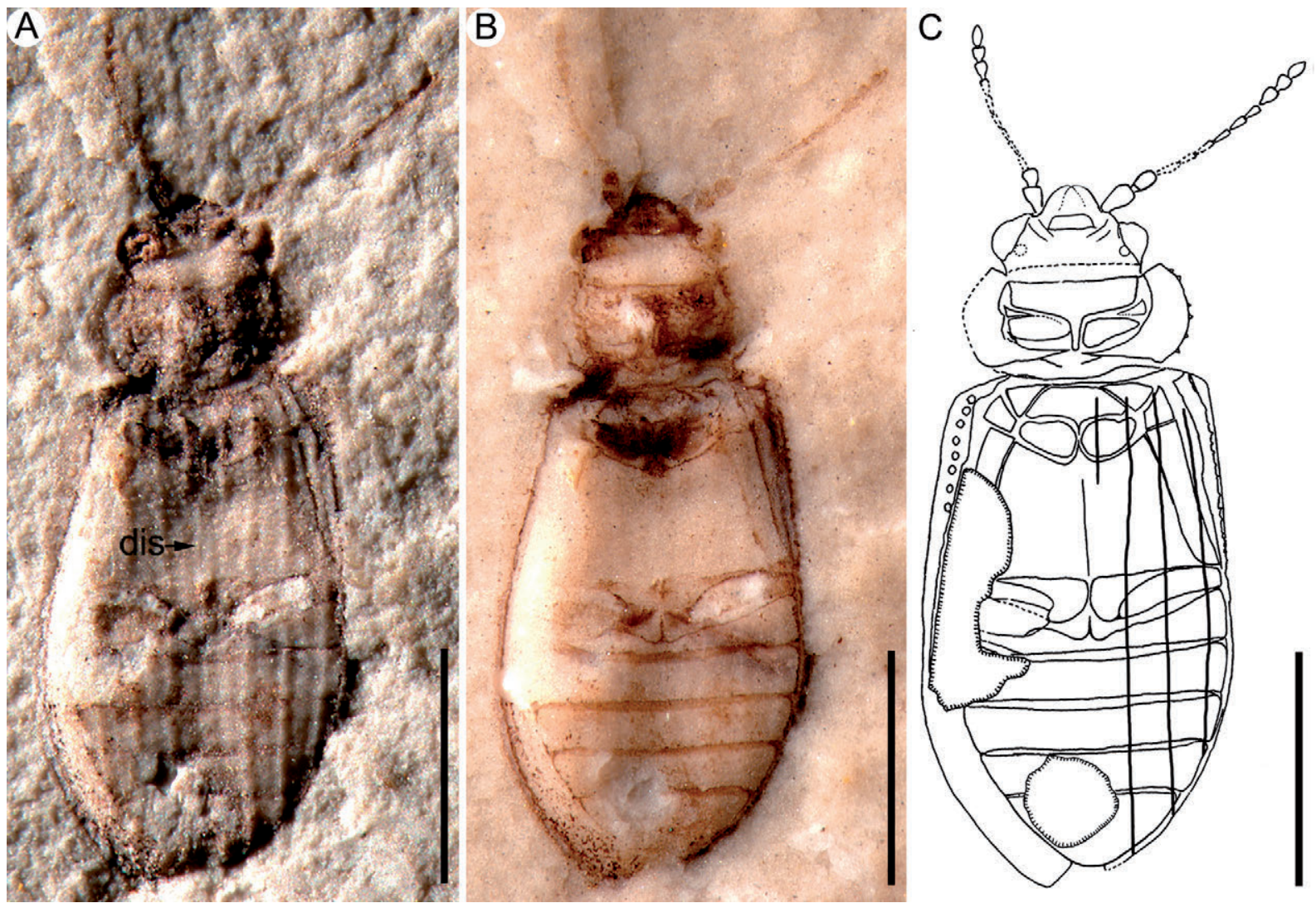

Fig. 1. Juropeltastica sinica gen. n. sp. n., holotype, habitus. A - under low-angled light; B - moistened with $70 \%$ alcohol; C - line drawing. Abbreviation: dis - discrimen. Scale bars $1 \mathrm{~mm}$.

\section{SYSTEMATIC PALEONTOLOGY}

Order: Coleoptera Linnaeus, 1758

Family: Derodontidae LeConte 1861

Subfamily: Peltasticinae LeConte, 1861

\section{Genus: Juropeltastica gen. $\mathbf{n}$.}

Type species. Juropeltastica sinica sp. n., here designated.

Diagnosis. Body small. Head with frontal raised area delimited laterally and posteriorly by grooves. Antenna 11-segmented, with a loose 3-segmented club. Pronotum weakly explanate; lateral margins toothed/crenulate. Procoxae distinctly separated, transverse; protrochantins exposed. Procoxal cavities externally closed. Elytron with one short mesobasal and three complete longitudinal carinae. Epipleural rim with a row of relatively large round window punctures. Mesocoxal cavities transverse, broadly open laterally, closed by mesepimeron and metanepisternum. Metaventral discrimen present. Metacoxae contiguous, excavate, extending laterally to rim of elytra. Abdominal ventrite 1 very short, without parallel ridges. Ventrites $2-5$ each with a pair of small curved basolateral ridges.

Etymology. The name of the genus is a combination of Juro-, meaning "Jurassic", and the genus Peltastica; it is feminine in gender.

\section{Juropeltastica sinica sp. n. (Figs 1-3)}

Diagnosis. As for the genus (see above).

Description. Body $2.91 \mathrm{~mm}$ long, densely and coarsely punctate.
Head (Fig. 2A) prognathous, transverse, $0.39 \mathrm{~mm}$ long and $0.67 \mathrm{~mm}$ wide; not abruptly constricted to form a neck region; temples and transverse occipital ridge absent. Frontoclypeal suture not visible. Frontal region elevated, anteriorly concave or emarginate, posteriorly delimited by deep, converging lateral grooves (Fig. 2A) joining broader transverse channel extending laterally behind the tubercles adjacent to compound eyes. Antennal grooves not visible. Eyes relatively large, laterally protruding. Ocelli (Fig. 2A) present, adjacent to the inner margins of eye. Antennal scape and pedicel (Fig. 2D) broad and subequal in length; antennomere 3 apparently elongate; antennomeres 4-8 longer than wide and decreasing in length; antennomeres 9 and 10 subquadrate; antennomere 11 conical. Antennal insertions apparently concealed. Mandible curved. Postgena covered with relatively large round punctures.

Pronotum (Fig. 2A) transverse, with dense round punctures, wider than head, $0.44 \mathrm{~mm}$ long and $0.97 \mathrm{~mm}$ wide; weakly explanate. Prosternum (Fig. 2C) in front of coxae about as long as longitudinal coxal diameter; prosternal process (Fig. 2C), narrow, parallel-sided with rounded apex. Procoxae transverse; protrochantins exposed; procoxal cavities strongly transverse, externally closed by relatively narrow notal projections. Elytra (Fig. 2E) complete, length $2.10 \mathrm{~mm}$, combined width $1.32 \mathrm{~mm}$. Each elytron with three complete longitudinal carinae on intervals 3, 5 and 7 and a short additional carina on interval 1, which does not extend beyond anterior fifth (Fig. 2E). Epipleural rim well developed, gradually narrowing 

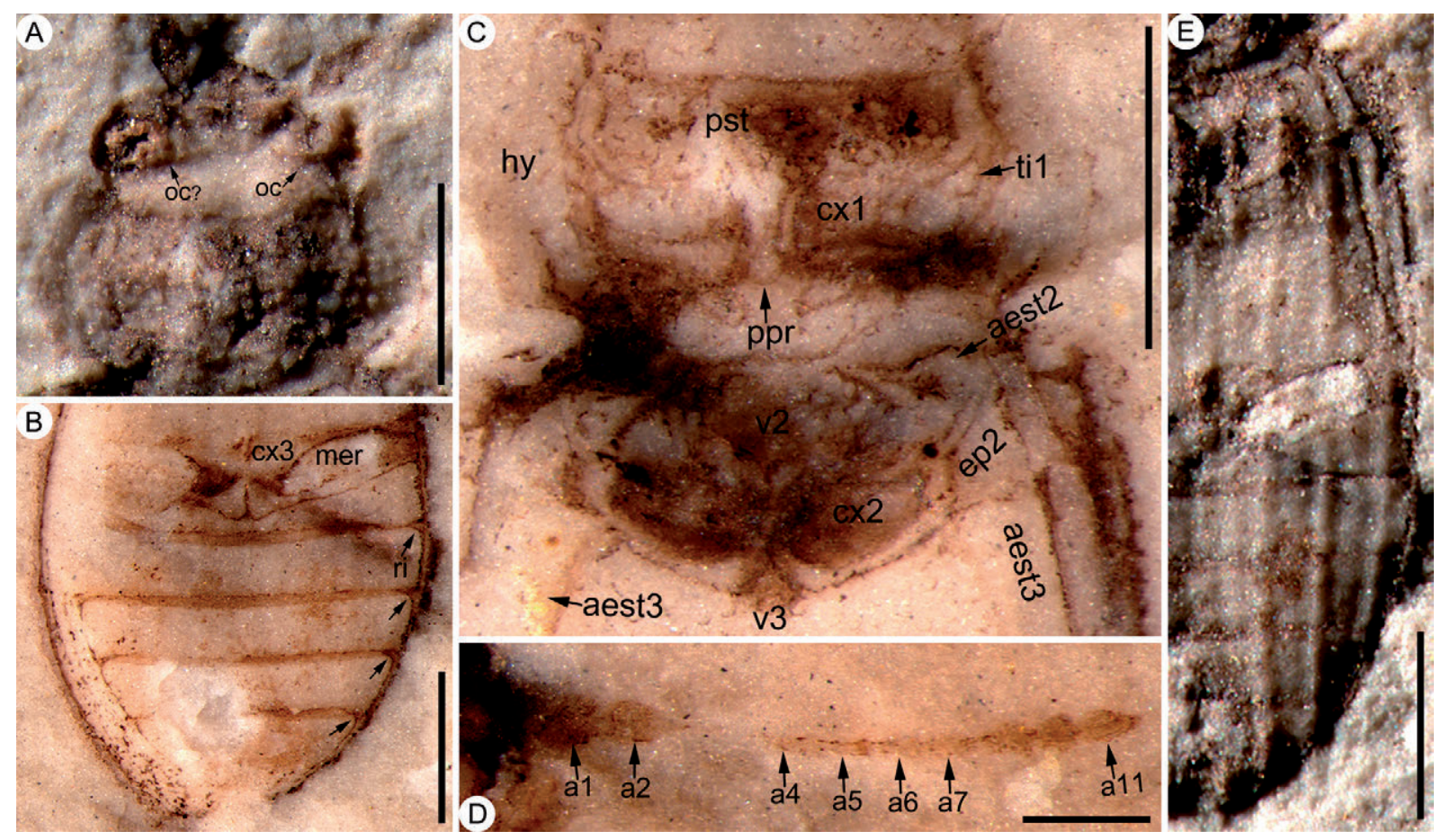

Fig. 2. Juropeltastica sinica gen. n. sp. n., holotype, details. A - head and prothorax, with ocelli indicated; B - metacoxae and abdomen; C - prothorax and mesothorax; D - right antenna; E - right eytron. A and E under low-angled light; others moistened with $70 \%$ alcohol. Abbreviations: a - antennomere; aest $2 / 3$ - mes-/metanepisternum; cx1/2/3 - pro-/meso-/metacoxa; ep 2 - mesepimeron; hy - hypomeron; mer - metacoxal meron; oc - ocellus; ppr - prosternal process; pst - prosternum; ri - ridge; til - protrochantin; v2/3 meso-/metaventrite. Scale bars $200 \mu \mathrm{m}$ in D, $500 \mu \mathrm{m}$ in others.

from base to half of elytron. Mesocoxae (Fig. 2C) almost contiguous; mesocoxal cavities transverse and oblique, broadly open laterally (Fig. 2C). Mesoventrite very short, punctate, separated by complete sutures from mesanepisterna; procoxal rests absent. Metaventrite very large, with dense round punctures, wider than long; discrimen present. Metanepisternum elongate, slightly narrowing posteriorly, inner posterior angle broadly rounded. Metacoxae (Fig. 2B) strongly transverse and probably excavate near base, contiguous, extending laterally to meet elytra.

Abdomen (Fig. 2B) with five free ventrites; intercoxal process of abdomen very narrow and acute; ventrites 2 and 3 subequal; ventrite 4 shorter than 3; ventrite 5 the longest.

Material. Holotype: Only one piece of impression fossil included, without counterpart, NIGP157738. The fossil beetle is an adult, with more ventral structures visible than dorsal ones. Maxillary palps, labial palps and legs not preserved.

Locality. Middle Jurassic Jiulongshan Formation at Daohugou, Ningcheng County, Inner Mongolia, Northeast China. The site was a relatively large lake surrounded by a forest containing, among other, conifers, ferns and Ginkgoales. The palaeoclimate of Daohugou was probably warm temperate based on the entomofauna (Ren et al., 2010).

Etymology. Derived from the country (China) where the type species comes from.

\section{DISCUSSION}

Although in general habitus Juropeltastica sinica is superficially similar to some members of the cucujoid family Latridiidae and the subfamily Dasycerinae of the staphylinoid family Staphylinidae, it is easily separated from mem- bers of either group by the large transverse procoxae with exposed trochantins, open mesocoxal cavities laterally closed by mesepimeron and metanepisternum, large, contiguous and excavate metacoxae and short first abdominal ventrite. Additionally, it may be distinguished from Dasycerinae by the distinctly separated procoxae, posteriorly closed procoxal cavities and the abdomen with five ventrites (six in Dasycerinae).

Juropeltastica is placed in the Recent small family Derodontidae based on the overall body shape and size, dorsal surfaces of head with canals and elevations, toothed/ crenulate pronotal lateral margins, open mesocoxal cavities bordered by mesepimeron and metanepisternum, and excavate metacoxae (Leschen, 2002). In addition, the combination of 11-segmented antennae with 3-segmented club, distinctly separated procoxae, exposed protrochantins, developed metaventral discrimen, contiguous and strongly transverse metacoxae extending laterally to rim of elytra, and 5-segmented abdomen also supports this assignment. Most modern adults of Derodontidae are also characterized by the presence of a pair of ocelli, which are more or less close to compound eyes (e.g., Lawrence \& Hlavac, 1979; Lawrence, 1985; Leschen \& Beutel, 2004; see exceptions in Leschen, 2011). Due to the insufficient preservation of the holotype, ocelli are not clearly shown from the mainly ventral-aspect impression fossil. However, a relatively large round tubercle is present and adjacent to the inner margin of the left eye, which is morphologically similar to the ocellus found in extant members of Peltastica. The presence of paired curved basolateral ridges (although 
small) on ventrites 2-5, clearly shown in at least Derodontus and Peltastica, also supports the placement. Another interesting character of extant derodontids is that the inner posterior angle of metanepisternum is broadly rounded, a feature also found in the new genus Juropeltastica.

Derodontidae currently comprises three subfamilies: Peltasticinae (Peltastica), Derodontinae (Derodontus) and Laricobiinae (Laricobius and Nothoderodontus) (e.g., Háva 2006; Lawrence \& Hlavac, 1979). The new genus Juropeltastica can be attributed to the extant subfamily Peltasticinae as evidenced by the more or less explanate pronotum, carinate elytra, and simple first visible abdominal ventrite lacking ridges near midline (Lawrence \& Hlavac, 1979). Juropeltastica appears to combine features belonging to the genera Peltastica and Derodontus. It shares with Peltastica the explanate pronotum and elytra, subcontiguous mesocoxae, relatively short first abdominal ventrite lacking ridges, and elytra bearing carinae (the latter tuberculate in Peltastica); and shares with Derodontus the relatively narrow pronotum and densely punctate postgena, prosternum, and meso- and metaventrite.

Since no definitive fossil derodontids are known to date, the new discovery of a definite derodontid of the Mesozoic age is undoubtedly of great significance for understanding the origin and early evolutionary history of the family Derodontidae, and even for the superfamily Derodontoidea. The find of a new derodontid genus from the Middle Jurassic (ca. $165 \mathrm{Ma}$ ) of China suggests that the Derodontidae may have originated sometime in the early Jurassic.

ACKNOWLEDGEMENTS. This research was supported by National Basic Research Program of China (2012CB821903), Outstanding Youth Foundation of Jiangsu Province (BK 2012049), and the National Natural Science Foundation of China (91114201 and J1210006).

\section{REFERENCES}

Beutel R.G. 1996: Study of the larva of Nosodendron fasciculare (Olivier 1790) (Coleoptera, Nosodendridae) with implications for the phylogeny of Bostrichiformia. - J. Zool. Syst. Evol. Res. 34: 121-134.

Bocak L., Barton C., Crampton-Platt A., Chesters D., Ahrens D. \& Vogler A.P. 2014: Building the Coleoptera tree-of-life for $>8000$ species: composition of public DNA data and fit with Linnaean classification. - Syst. Entomol. 39: 97-110.

Crowson R.A. 1959: Studies on the Dermestoidea (Coleoptera), with special reference to the New Zealand fauna. - Trans. $R$. Entomol. Soc. Lond. 111(4): 81-94.

Crowson R.A. 1980: On amphipolar distribution patterns in some cool climate groups of Coleoptera. - Entomol. Gener. 6: $281-292$.

Franz J. M. 1958: Studies on Laricobius erichsonii Rosenh. (Coleoptera: Derodontidae): a predator on chermesids. - Entomophaga 3: 109-196.
Ge S.-Q., Beutel R.G. \& YANG X.-K. 2007: Thoracic morphology of adults of Derodontidae and Nosodendridae and its phylogenetic implications (Coleoptera). - Syst. Entomol. 32: 635-667.

HÁva J. 2006: A world catalogue of the family Derodontidae (Coleoptera). - Pol. Pismo Entomol. 75: 29-38.

Huang D.-Y., Nel A., Shen Y.-B., Selden P.A. \& Lin Q.-B. 2006: Discussions on the age of the Daohugou fauna - evidence from invertebrates. - Prog. Nat. Sci. 16: 308-312.

Hunt T., Bergsten J., Levkanicova Z., Papadopoulou A., St. John O., Wild R., Hammond P.M., Ahrens D., Balke M., CAterino M.S., Gómez-Zurita J., Ribera I., Barraclough E.G., Bocakova M., BocaK L. \& Vogler A.P. 2007: A comprehensive phylogeny of beetles reveals the evolutionary origins of a superradiation. - Science 318: 1913-1916.

Lawrence J.F. 1982: Coleoptera. In Parker S.P. (ed.): Synopsis and Classification of Living Organisms. Vol. 2. McGraw-Hill, New York, pp. 482-553.

Lawrence J.F. 1985: The genus Nothoderodontus (Coleoptera: Derodontidae) with new species from Australia, New Zealand and Chile. In Ball G.E. (ed.): Taxonomy, Phylogeny and Zoogeography of Beetles and Ants. W. Junk, Dordrecht, pp. 68-83.

Lawrence J.F. \& Hlavac T.F. 1979: Review of the Derodontidae (Coleoptera: Polyphaga) with new species from North America and Chile. - Coleopts. Bull. 33: 369-414.

Lawrence J.F. \& Newton A.F. 1995: Families and subfamilies of Coleoptera (with selected genera, notes, references and data on family-group names). In Pakaluk J. \& Ślipiński S.A. (eds): Biology, Phylogeny, and Classification of Coleoptera: Papers Celebrating the 80th Birthday of Roy A. Crowson. Muzeum i Instytut Zoologii PAN, Warszawa, pp. 779-1006.

Lawrence J.F., Ślipiński A., Seago A.E., Thayer M.K., Newton A.J. \& Marvaldi A.E. 2011: Phylogeny of the Coleoptera based on morphological characters of adults and larvae. - Ann. Zool. (Warszawa) 61: 1-217.

LESCHEN R.A.B. 1994: Fungal host use in two species of Derodontus (Coleoptera: Derodontidae). Coleopts. Bull. 48: 126-130.

LesChEN R.A.B. 2002: 66. Derodontidae LeConte 1861. In Arnett R.H. Jr., Thomas M.K., Skelley P.E. \& Frank J.H. (eds): American Beetles. Vol. 2. Polyphaga: Scarabaeoidea through Curculionoidea. CRC Press, Boca Raton, FL, pp. 221-223.

LESCHEN R.A.B. 2011: World review of Laricobius (Coleoptera: Derodontidae). - Zootaxa 2908: 1-44.

Leschen R.A.B. \& Beutel R.G. 2004: Ocellar atavism in Coleoptera: plesiomorphy or apomorphy? - J. Zool. Syst. Evol. Res. 42: 63-69.

Leschen R.A.B. \& Beutel R.G. 2010: 5.1. Derodontidae LeConte, 1861. In Leschen R.A.B., Beutel R.G. \& Lawrence J.F. (eds): Handbook of Zoology. Vol. IV Arthropoda: Insecta Part 38. Coleoptera, Beetles. Vol. 2. Morphology and Systematics (Polyphaga partim). W. DeGruyter, Berlin, pp. 180-185.

Ren D., Shin C.-K., Gao T.-P., Yao Y.-Z. \& Zhao Y. 2010: Silent Stories - Insect Fossil Treasures from Dinosaur Era of the Northeastern China. Science Press, Beijing, 322 pp.

Yu G. \& Montgomery M.E. 2007: A new species of Laricobius (Coleoptera: Derodontidae) from Taiwan. - Formosan Entomol. 27: 341-347.

Received January 23, 2014; revised and accepted March 24, 2014 Prepublished online April 4, 2014 